\title{
Health benefits of physical activity with special reference to interaction with diet
}

\author{
IM Vuori* \\ UKK Institute for Health Promotion Research, Tampere, Finland
}

\begin{abstract}
Regular physical activity causes numerous and substantial performance-improving and health-enhancing effects. Most of them are highly predictable, dose-dependent and generalizable to a wide range of population groups. Many of the biological effects of regular, moderate physical activity translate into substantially reduced risk of coronary heart disease, cerebrovascular disease, hypertension, maturity onset diabetes, overweight and obesity, and osteoporosis. These effects also substantially reduce the risk of deterioration of functional capacity. In the genesis of these conditions, a lack of physical activity and inadequate nutrition act synergistically and in part additively, and they operate largely through the same pathways. It is conceivable to suggest that the prevalence of, e.g, the above mentioned metabolic diseases is so high in Europe largely because of the high prevalence of sedentariness and inadequate nutrition. Thus, both physical activity and nutrition have to be given strong emphasis in policies, strategies and programmes that will be developed and implemented for improving the health of Europeans.
\end{abstract}

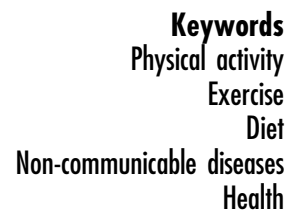

Traditionally, regular exercise in moderation has been considered healthy. During the last decades scientific evidence has accumulated to show a wide array of health benefits of regular physical activity (Table 1$)^{1}$. The size of many of these benefits (Table 2 , see also Table 3$)^{2}$ is considerable and comparable to those of other modifiable measures such as lifestyles and drugs. In most, particularly biological benefits a dose-response is seen. This means that many benefits begin to accrue when the activity increases even modestly above the sedentary level and continue to increase until high intensity and/or large amount of activity (Fig. 1) ${ }^{3}$. This knowledge has led to wide endorsement of a public health recommendation of physical activity ${ }^{4}$ :

Every adult should accumulate 30 minutes of moderateintensity physical activity on most, preferably all days of the week.

An example of moderate-intensity physical activity is brisk walking which will leave the participant slightly out of breath, but still able to talk to a person accompanying them. This type of exercise is moderate in nature and it can be accumulated in several bouts throughout the day, carried out as a part of everyday life.

People who are currently sedentary or minimally active should gradually build up to the goal of 30 minutes of moderate activity daily by adding a few minutes each day, to reduce the musculoskeletal risks associated with suddenly increasing the amount or intensity of exercise.
Those who currently meet these standards may derive additional health and fitness benefits by becoming more physically active or including more vigorous activity.

For young people the corresponding recommendation based on less evidence and not yet widely accepted, reads as follows ${ }^{5}$ :

All young people (5-18 years) should participate in physical activity of at least moderate intensity for one hour per day.

These new recommendations have great practical significance by giving quantitative targets that can be reached by reasonable use of time, effort and economic resources. Considering the multiple benefits and feasibility of regular moderate physical activity it has a very large health potential. An example is given in Table 3 indicating that the population attributable risk of physical inactivity among middle-aged Finnish men is between 22 and 39\% and greater than that of smoking, elevated cholesterol, elevated blood pressure or overweight in the same populations. Recent pan-European survey suggests that only a minor part of this potential is currently in use (Table 4) ${ }^{6}$.

\section{Mechanisms of action}

Basically physical activity consists of various types of physical loading that stimulate organs and organ systems in different ways. Fig. 2 illustrates that practically all organ 
Table 1 The health benefits of regular physical activity (adapted from Haskell 1998) ${ }^{1}$. Based on a total physical fitness program that includes physical activity designed to improve both aerobic and musculoskeletal fitness

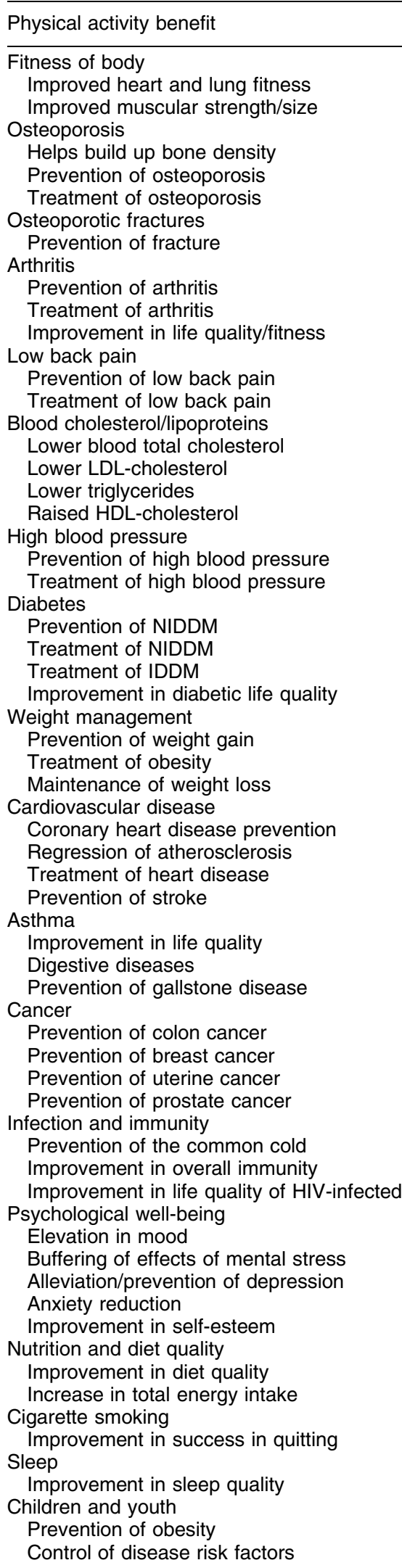

Table 1. continued

\begin{tabular}{lc}
\hline Physical activity benefit & Surety rating \\
\hline Reduction of unhealthy habits & $\dagger$ \\
Improved odds of adult activity & $\dagger$ \\
Special issues for women & \\
Improved total body fitness & $\S$ \\
Improved fitness while pregnant & $\S$ \\
Improved birthing experience & $\dagger$ \\
Improved health of fetus & $\dagger$ \\
Improved health during menopause & $\ddagger$ \\
Elderly and the aging process & $\S$ \\
Improvement in physical fitness & $\dagger$ \\
Countering of loss in heart/lung fitness & $\ddagger$ \\
Countering of loss of muscle & $\ddagger$ \\
Countering of gain in fat & $\S$ \\
Improvement in life expectancy & $\S$ \\
Improvement in life quality & \\
\hline * Little or no data support. \\
† Some data are supportive, but much more research is needed. \\
₹ Most data are supportive, but more research is needed for clarification. \\
§ Strong consensus, with little or no conflicting data.
\end{tabular}

systems are involved in and respond to a bout of physical activity. Many of the acute responses show a doseresponse relationship to the intensity or amount of the activity. When the loading stimulus is repeated in suitable frequency, intensity and volume, structural or functional adaptations in the loaded organs can take place in order to better tolerate the loading. Most of the acute responses and practically all of the adaptive responses caused by activity that corresponds to the capabilities of the subject can be considered to enhance health, functional capacity or well-being either immediately or more often in the course of weeks, months or years and either directly or indirectly. Table 5 gives a number of examples of these effects. Also many of them show dose-response relationship (Fig. 1). Figure 3 illustrates some of the metabolic pathways that explain how regular physical activity

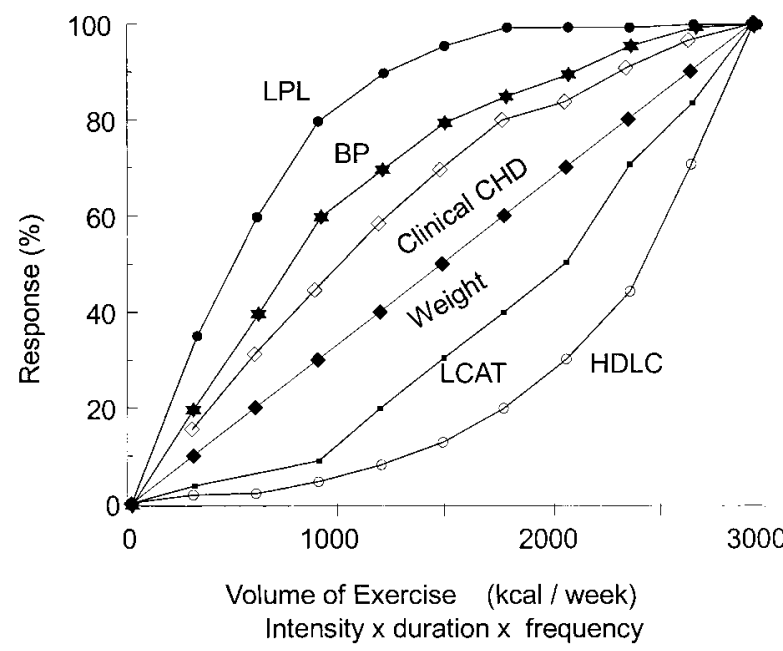

Fig. 1 Dose-response relationships between volume of exercise, biological responses, and coronary heart disease. Total CVD=total cardiovascular disease, $\mathrm{BP}=$ blood pressure, $\mathrm{HDL}-\mathrm{C}=$ high-density lipoprotein cholesterol ${ }^{3}$ 


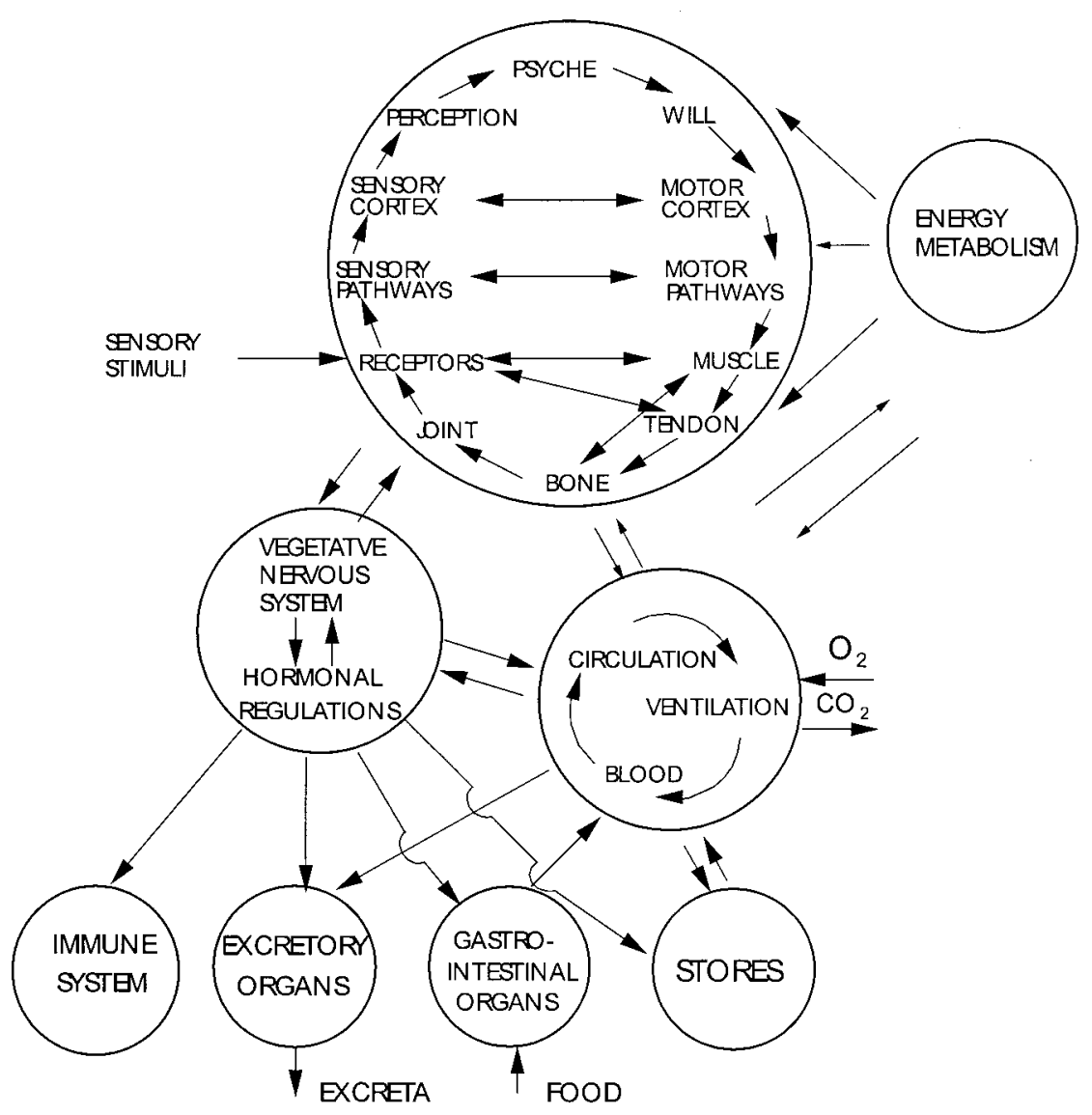

Fig. 2 A bout of physical activity creates functional responses not only in the organs primarily involved in the genesis of the muscular action (kinetic chain) but also in organs that serve the kinetic chain and maintain homeostasis of the whole organism

decreases the risk of cardiovascular diseases and Fig. 4 gives an example of interaction of physical (in)activity and diet in the development of a pathological process (atherosclerosis).

Most of the effects are unique to physical activity and they cannot be compensated by other means. If these effects are essential to and the sole or main part of a particular health-related outcome, the role of physical activity to attain that outcome is decisive and noncompensable. Maintenance of sufficient muscle strength

Table 2 Examples of the size of the effects on health of regular physical activity (comparison active vs. sedentary) (compiled from recent peer-reviewed publications, references available from the author)

\section{Aerobic capacity}

Functional limitations Osteoporotic fractures Obesity Hypertension

Non-insulin dependent diabetes

Coronary heart disease

Stroke

Colon cancer

All cause mortality
Decrease with aging up to $50 \%$ slower in active and activity delays the decline of aerobic capacity to level threatening independent living by $10-20$ years

Risk of developing functional limitations in elderly in $3-5$ years is $25-50 \%$ of that in active.

Risk of hip fractures $30-50 \%$ smaller in active

Prevalence of obesity and risk of becoming obese in active one half of that in sedentary

Risk of developing hypertension $30 \%$ smaller

Regular physical activity lowers normal blood pressure in average by $3 / 2 \mathrm{mmHg}$ and elevated blood pressure by $7 / 6 \mathrm{mmHg}$. Estimated population effects: $17 \%$ decrease in hypertension, $6 \%$ decrease in coronary heart disease and $15 \%$ in cerebrovascular disease

Risk of developing diabetes $20-60 \%$ smaller in active

Incidence decreased by $46 \%$ during 6 years in a large intervention study

Mortality risk in active one half of that in sedentary

Risk of events (fatal or nonfatal) in 40-65 years old women in 8 years $45 \%$ lower in those walking three or more hours per week at a brisk pace than in those who walked infrequently

Mortality risk in active one half of that in sedentary

Risk $40-50 \%$ smaller in active

Risk in 18 years in 26-64 years old same-sex twins: one half in active compared to sedentary Risk $19 \%$ lower per one mile walked per day in 12 years in 61-81 years old men

Risk decreased to half in 12-14 years in 40-59 years old men who began regular exercise

Risk decreased $30-50 \%$ in 13 years in $40-60$ years old men who improved their fitness level

Risk doubled in 6 years in 38-60 years old women who discontinued exercise 
Table 3 Comparison of effects of major CVD risk factors on population attributable risk in Finnish men (aged 30-63 years) ${ }^{2}$

\begin{tabular}{|c|c|c|c|c|c|}
\hline \multirow[b]{2}{*}{ Risk factor } & \multirow{2}{*}{$\begin{array}{l}\text { Prevalence of } \\
\text { the risk factor\% }\end{array}$} & \multicolumn{2}{|c|}{ Lowest } & \multicolumn{2}{|c|}{ Highest } \\
\hline & & $\mathrm{RR}$ & $\mathrm{PAR}^{\star} \%$ & $\mathrm{RR} \dagger$ & PAR $\%$ \\
\hline Sedentary living (activity $\leq 3$ times a week) & 71 & 1.4 & 22.1 & 1.9 & 39.0 \\
\hline Current smoking & 35 & 1.3 & 9.5 & 2.4 & 32.9 \\
\hline Cholesterol level $(\geq 6.5 \mathrm{mmol} / \mathrm{l})$ & 26 & 1.4 & 9.4 & 2.0 & 20.6 \\
\hline $\begin{array}{l}\text { Hypertension }(\mathrm{SBP} \geq 160) \neq \\
\text { Oyerweight }\end{array}$ & 15 & 1.4 & 5.7 & 2.2 & 15.3 \\
\hline$(\mathrm{BMI}>30) \S$ & 19 & 1.2 & 3.7 & 1.4 & 7.1 \\
\hline$(\mathrm{BMI} \geq 27)$ & 37 & 1.2 & 6.9 & 1.4 & 12.9 \\
\hline
\end{tabular}

${ }^{*}$ PAR $=$ Population attributable risk.

$\dagger \mathrm{RR}=$ Relative risk; lowest and highest relative risk from different studies. $\ddagger$ SBP $=$ Systolic blood pressure.

$\S \mathrm{BMI}=$ Body mass index.

or endurance performance capacity are examples of these types of health-related benefits of physical activity. Most health-related outcomes are influenced by several factors, however. Also in these cases physical activity may have an essential and quantitatively substantial role related to the development of a particular health outcome. Examples of these effects are stimulation of bone formation to attain and maintain sufficient bone mass, maintenance of sufficient energy expenditure to maintain energy balance and healthy body weight or maintenance of adequate cellular insulin action to allow normal usage of sugar in energy production. These types of effects are necessary for all and signify the essential role of physical activity for good health. In some health outcomes such as coronary heart disease and colon cancer physical activity brings the benefit primarily in indirect ways, e.g. by influencing other, causal risk factors (see below, coronary heart disease). In these cases physical activity has a contributory role. Its size and necessity depends on the level and type of the risk factors of the given disease in the individual. For example, obesity, elevated blood pressure, insulin resistance and low HDL-cholesterol indicate both great biological potential and great need of physical activity for prevention of coronary heart disease in the individual. In some health outcomes the beneficial role of physical activity is indirect and poorly predictable, e.g. decreased smoking and improved diet due to increased health consciousness associated with adoption of regular exercise habit.

In the following a short description of the major established health benefits of physical activity including the main mechanisms is given.

\section{Physical fitness - performance capacity:}

\section{Cardiovascular, endurance or aerobic fitness}

Feasible exercise training increases maximal aerobic power (maximal oxygen uptake, $\mathrm{VO}_{2} \max$ ) by $10-20 \%$ and performance time at submaximal level substantially more in healthy sedentary individuals, men and women, young and old. The mechanisms include increased muscular vascularisation, perfusion, fat oxidation, glycogen stores and oxygen extraction, decreased glycogen use and lactate production, ventilation and shortness of breath, increased insulin sensitivity; increased plasma and red cell volume, improved cardiac efficiency,

Table 4 Proportion of adults in the EU countries who spend 3 hours or less in a week in recreational physical activity. (Current recommendation is 30 minutes a day or more of physical activity on most, preferably all days of the week) ${ }^{21}$

\begin{tabular}{|c|c|c|c|c|}
\hline & None \% & $<1$ hour $\%$ & $1-3$ hours $\%$ & None to 3hours (less than recommended) \\
\hline EU average* & 32 & 7 & 18 & 57 \\
\hline Austria & 16 & 4 & 18 & 38 \\
\hline Belgium & 42 & 7 & 18 & 67 \\
\hline Denmark & 24 & 6 & 16 & 46 \\
\hline Finland & 10 & 5 & 18 & 33 \\
\hline France & 36 & 7 & 20 & 63 \\
\hline Germany & 31 & 6 & 19 & 56 \\
\hline Greece & 40 & 4 & 18 & 62 \\
\hline Ireland & 14 & 5 & 16 & 35 \\
\hline Italy & 39 & 7 & 20 & 66 \\
\hline Luxembourg & 20 & 8 & 19 & 47 \\
\hline Netherlands & 19 & 6 & 18 & 43 \\
\hline Portugal & 61 & 7 & 15 & 83 \\
\hline Spain & 37 & 11 & 17 & 65 \\
\hline Sweden & 12 & 4 & 16 & 32 \\
\hline UK & 24 & 7 & 17 & 48 \\
\hline
\end{tabular}


Table 5 Physiological effects of regular physical activity (exercise training) (compiled by Vuori from numerous sources)

\begin{tabular}{|c|c|}
\hline Structure of function & Effect \\
\hline \multicolumn{2}{|l|}{ Muscle } \\
\hline Myofibrils & Number and cross-sectional area increase \\
\hline Connective tissue & Amount increases, also in tendons and ligaments \\
\hline Protein synthesis & Increases, leads to hypertrophy \\
\hline Strength and power & Increase $(\sim \times 2)$, initially due to neural mechanisms \\
\hline Endurance & Increases as a result of endurance activities \\
\hline Bone & Size, cortical thickness and mass increase but only locally \\
\hline \multicolumn{2}{|r|}{ 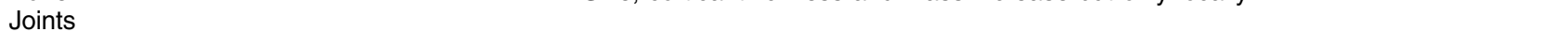 } \\
\hline Cartilage & Nutrition improves \\
\hline Capsul, ligaments & Collagen synthesis and tensile strength increase \\
\hline Mobility & Is maintained or improves \\
\hline \multicolumn{2}{|l|}{ Metabolism } \\
\hline ATP, creatine phosphate & Increase slightly (in speed training) \\
\hline Lactacid energy production & Power increases (in speed-endurance training) \\
\hline Mitochondria & Volume increases \\
\hline Oxidative enzymes & Activity increases leading to increased fat oxidation and increased endurance capacity \\
\hline Intramuscular triglycerides & Stores increase \\
\hline Serum triglycerides & Decreased, if activity frequent and in lengthy bouts \\
\hline Lipoprotein lipase & Activity increases \\
\hline Hepatic lipase & Activity decreases or no change \\
\hline LCAT & Activity increases \\
\hline CETP & Activity increases \\
\hline Total cholesterol & No change or small decrease \\
\hline VLD-lipoprotein & Decreases \\
\hline LD-lipoprotein & Decreases or no change \\
\hline Small LDL & Decreases \\
\hline HD-lipoprotein & Increases \\
\hline $\mathrm{HDL}_{2}-\mathrm{C}$ & increases \\
\hline $\mathrm{HDL}_{3}-\mathrm{C}$ & Decreases or no change \\
\hline Glycogen in liver, muscles & Increases \\
\hline Lactate production, concentration & Decreases in submaximal and increases at maximal work load \\
\hline Lactate elimination & Increases \\
\hline Myoglobin & Concentration increases \\
\hline Temperature regulation & Improves \\
\hline \multicolumn{2}{|l|}{ Ventilation } \\
\hline Minute volume & Decreases in submaximal and increases at maximal work load \\
\hline \multicolumn{2}{|l|}{ Circulation } \\
\hline \multicolumn{2}{|l|}{ Heart } \\
\hline Left ventricle & Mass increases at intensive training \\
\hline End-diastolic volume & Increases due to increased filling (increased blood volume) \\
\hline Contractility & Possibly increases slightly \\
\hline Stroke volume & Increases \\
\hline Rate & Decreases due to autonomic nervous system regulation \\
\hline Rate variability & Possibly increases in prolonged intensive endurance training \\
\hline Minute volume & No change at rest and at submaximal work load, increases at maximal work load \\
\hline Impulse conduction & Disturbances increase \\
\hline Coronary arteries & Dilatation capacity increases \\
\hline Collaterals and capillaries & Increase shown only in experimental animals \\
\hline \multicolumn{2}{|l|}{ Peripheral circulation } \\
\hline Capillaries & Increase in muscles \\
\hline Blood pressure & Decreases \\
\hline Muscle blood flow & Decreases at rest and submaximal work load, increases at maximal work load \\
\hline Resistance & Decreases at least at maximal work load \\
\hline$a-v$ oxygen difference & Increases \\
\hline \multicolumn{2}{|l|}{ Blood } \\
\hline Plasma volume & Increases \\
\hline Red cell mass & Increases \\
\hline 2-3-DPG activity & Increases improving oxygen dissociation \\
\hline Fibrinolysis & Increases transiently after an activity bout \\
\hline Thrombocyte aggregation & Decreases transiently after an activity bout \\
\hline Aerobic power, $\mathrm{VO}_{2} \max$ & In creases mainly due to increased stroke volume and a-v $\mathrm{O}_{2}$-difference \\
\hline Aerobic endurance & In creases mainly due to improved fat oxidation \\
\hline \multicolumn{2}{|l|}{ Neuroendocrine regulation } \\
\hline Adrenaline concentration & Decreases at submaximal, increases at maximal work load \\
\hline Noradrenaline concentration & Decreases at submaximal, increases at maximal work load \\
\hline Growth hormone concentration & Decreases at submaximal work load \\
\hline Cortisol concentration & Decreases at submaximal work load \\
\hline Insulin concentration & Decreases at submaximal work load \\
\hline Insulin sensitivity & Increases in muscle and adipose tissue cells \\
\hline Testosterone concentration & Increases in moderate, decreases in heavy training \\
\hline
\end{tabular}




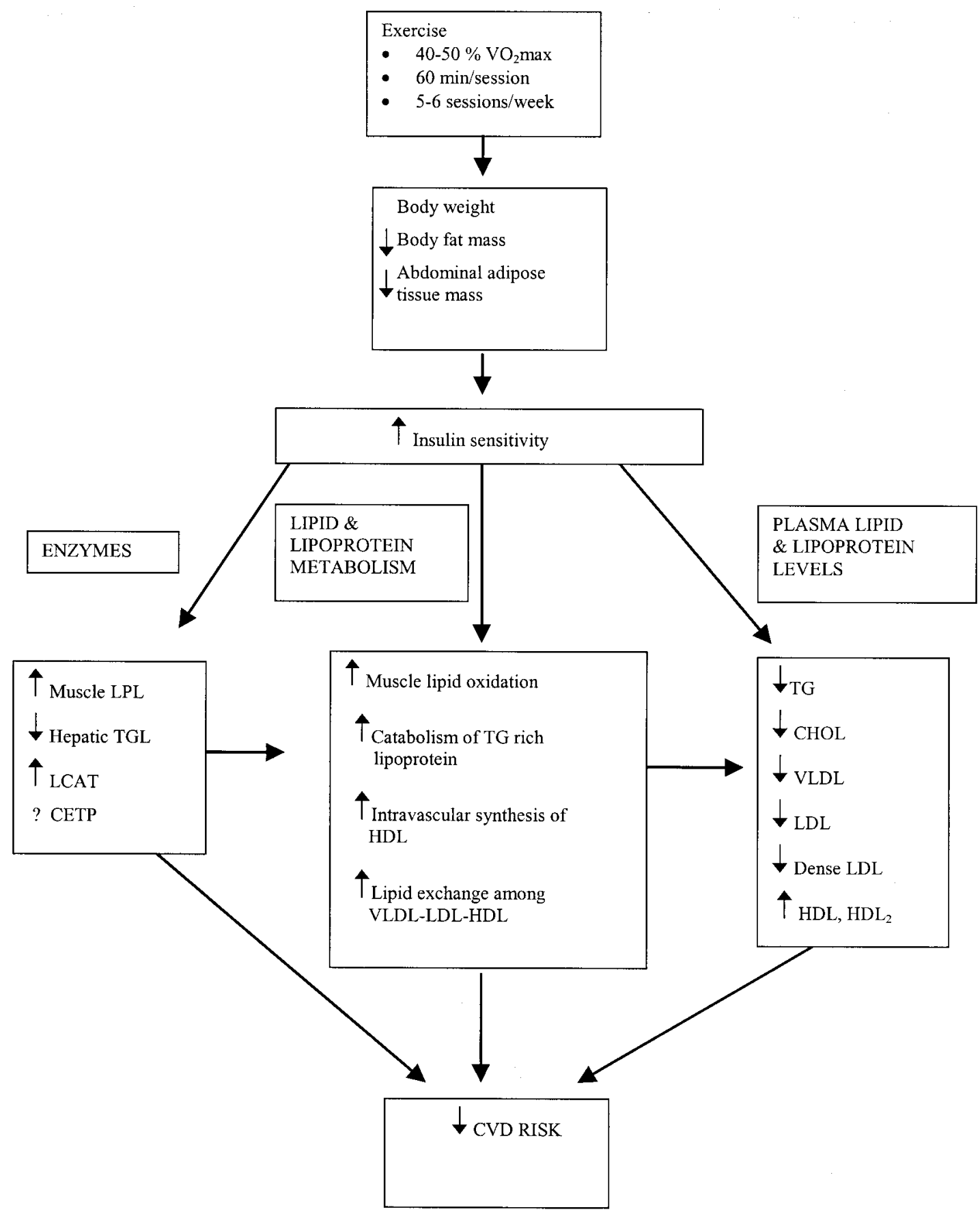

Fig. 3 Metabolic changes caused by regular physical activity that contribute to prevention, slower progression or eventually regression of atherosclerosis and lower risk of cardiovascular disease (adapted from C. Bouchard ${ }^{78}$ )

improved temperature regulation and increased psychological tolerance of effort ${ }^{7}$.

\section{Strength and power}

Also muscular strength and power can be increased by feasible exercise training at least in the same degree as endurance fitness, and these effects can be seen even in very old individuals. The underlying mechanisms include improved nervous control, increased muscle mass (contractile protein, collagen), and increased psychological effort tolerance ${ }^{8}$. A sufficient amount of protein in the diet is necessary for optimal effectiveness of physical activity.

\section{Osteoporosis and osteoporotic fractures}

Intensive activity which causes microscopic transient changes in the bone structure (strains) stimulates locally bone formation and consequently bone mass may 


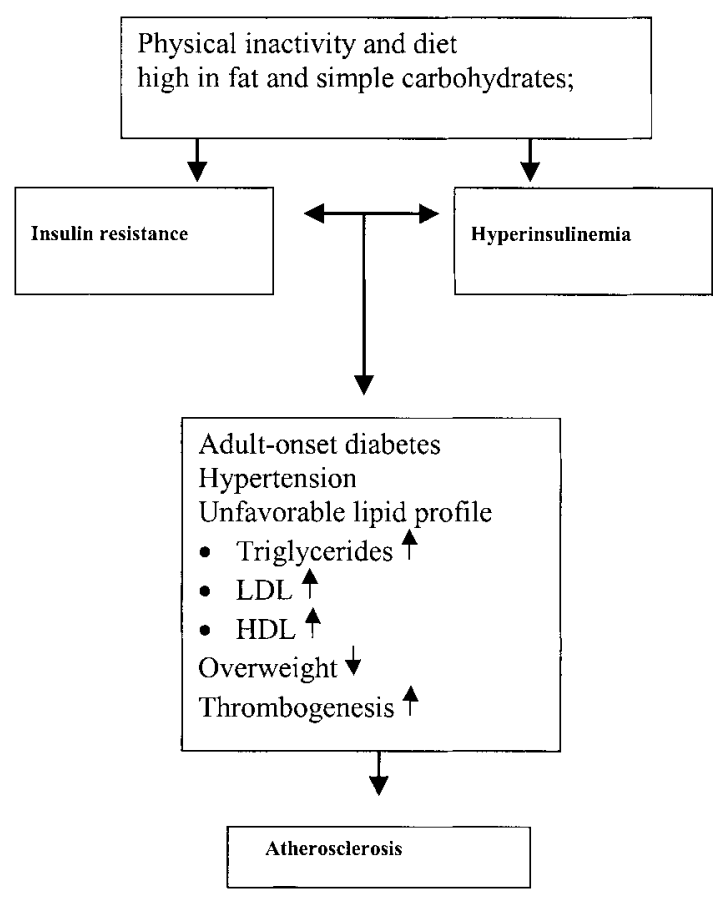

Fig. 4 Interaction of diet and physical (in)activity in the pathogenesis of atherosclerosis (modified from Barnard and Wen ${ }^{79}$ )

increase at that site. This effect may exceed 20\% in athletes 9 and is $5-15 \%$ in physically active as compared with sedentary adults ${ }^{10}$. If this change takes place in location where fracture risk is high and the benefit is maintained by continuous activity, the fracture risk will decrease. 'Permissive' milieu provided by e.g. adequate levels of estrogen and calcium is essential. Thus, both physical activity and adequate diet are essential for attaining and maintaining sufficient bone strength. Physical activities that maintain or improve coordination, balance, strength and other neuromuscular factors that influence risk of falling may decrease the fracture risk as evidenced by several epidemiological studies ${ }^{11-15}$.

\section{Artbritis}

Regular physical activity such as ordinary weight bearing activities done on daily basis is necessary for maintaining normal muscle strength, joint structure and joint function. These qualities help to protect joints from injuries, abnormal movements and limited range of motion, and secure nutrition of the joint cartilage and lubrication of joint surfaces. Regular physical activity also helps in maintaining healthy weight. All these effects contribute to maintenance of healthy joints ${ }^{4}$. In patients with degenerative and rheumatic arthritis physical activity programs consisting of parts aiming at cardiovascular conditioning, improvement in strength, added flexibility and increased joint mobility have resulted in better function and less symptoms ${ }^{4,16}$. Occupational or recreational activities that expose a joint to excessive impacts, pressure, range of motion or injuries increase the risk of developing osteoarthritis $^{4,17}$

\section{High blood pressure}

Regular moderate physical activity as well as good physical fitness prevent the development of hypertension in mild to moderate degree and that type of activity lowers elevated blood pressure in male and female patients of various ages having mild to severe hyperten$\operatorname{sion}^{4,18}$. The mechanisms include attenuation of adrenergic sympathetic activity, increased cellular insulin sensitivity and decreased level of circulating insulin, decreased peripheral resistance, increased baroreflex sensitivity, changes in renin-angiotensin-aldosterone system and reduction in body fat ${ }^{19}$. Improved relaxation/ decreased tension and anxiety are examples of indirect mechanisms. In patients with severe hypertension physical activity may lead to decrease of left-ventricular mass. The effects on blood pressure of physical activity and some dietary factors and drugs are additive.

\section{Non-insulin dependent diabetes Type 2 (NIDDM) or maturity onset diabetes (MODY)}

Regular physical activity lowers the risk of developing non-insulin-dependent diabetes mellitus by $20-60 \%$ in dose-related manner ${ }^{4,20-24}$. The size of the effect is greatest in subjects with high risk of $\mathrm{NIDDM}^{25}$. Both moderate to vigorous aerobic activities as well as resistance training are effective, and it is recommendable to practice them in combination ${ }^{26-27}$. The same applies to patients with NIDDM who benefit from physical activity in many and for them especially relevant ways: increased cellular insulin sensitivity and decreased need of insulin, lower blood insulin levels and peaks in blood sugar level, favourable changes in lipid metabolism and blood lipids, and improved weight control, physical fitness and $\operatorname{mood}^{28}$. The mechanisms by which physical activity improves insulin action and glucose metabolism in skeletal muscle include increased concentration of glucose - transporting protein (GLUT4), enhancement of insulin-mediated increase in muscle blood flow and glucose extraction in nonoxidative glycolysis, and increased glucose storage due to increased glycogen synthase. In addition, physical activity increases insulinmediated glucose uptake in adipose tissue and increases the insulin sensitivity and glucose storage capacity of the liver ${ }^{29-30}$. These changes occur in healthy subjects as well as in patients with NIDDM. Carefully individualized exercise programs are beneficial also for patients with insulin-dependent diabetes (Type 1, IDDM) ${ }^{31}$.

\section{Weight management}

Body weight is determined by the balance of diet and physical activity. Low levels of physical activity, resulting in less energy expenditure than consumed, contribute to the high prevalence of obesity in industrialized 
Table 6 Obesity-related diseases

\begin{tabular}{ll}
\hline $\begin{array}{l}\text { Weight reduction important for both } \\
\text { prevention and treatment }\end{array}$ & $\begin{array}{l}\text { Weight reduction or control } \\
\text { important for prevention }\end{array}$ \\
\hline NIDDM & Some cancers \\
Hypertension & Coronary heart disease \\
Abnormalities of lipid metabolism & Stroke \\
Sleep apnea syndrome & Gall stone disease \\
Arthrosis of lower leg joints & Complications of surgery and labour \\
Ventilatory insufficiency & Injuries \\
Impotence & \\
Psychosocial problems & \\
\hline
\end{tabular}

countries $^{32-37}$. It has come clear from hundreds of studies that without regular physical activity, weight control can usually not be achieved ${ }^{38}$. Physical activity alone is not particularly effective in producing substantial weight loss, but it is effective in the prevention of weight gain ${ }^{30-40}$. Physical activity is recommended as part of a comprehensive weight loss therapy and weight maintenance program because it modestly contributes to weight loss, may help with maintenance of weight loss, increases cardiorespiratory fitness $^{41}$ and appears to have an independent beneficial effect on several commodities of obesity $^{42}$.

Physical activity contributes to two parts of energy expenditure. First, it is essential in the development and maintenance of lean body mass that determines in major part the size of resting energy expenditure (approximately $60 \%$ of total energy expenditure). Physical activity is especially important to counteract the loss of muscle mass particularly in men after age $50^{43}$. Physical activity also may influence favourably distribution of body fat ${ }^{41,44}$. Secondly, physical activity itself increases the nonresting energy expenditure (about 30\% of the total) during the activity. Even nonexercise activity, activities of daily living, fidgeting, spontaneuous muscle contraction, and maintaining posture, may make a significant contribution to energy expenditure and be an important factor in the prevention of weight gain ${ }^{45}$. Thus, all kinds of physical activities of daily life are important for weight control ${ }^{46-47}$. The potential importance of physical activity for health through its effect on body weight can be estimated by the number, prevalence and severity of obesity-caused or related diseases ${ }^{41,48-49}$ (Table 6). The direct costs associated with obesity are estimated to represent 5.7 percent of the national health expenditure within the Unites States. The indirect costs are of the same magnitude and comparable to the economic costs of smoking $^{50}$. Importantly, higher levels of physical activity and physical fitness have been found to attenuate the increased risk of morbidity and mortality in overweight and obese persons ${ }^{51-53}$. It may be that the deleterious health effects of obesity are partly due to physical inactivity underlying the development and maintenance of obesity.

\section{Cardiovascular disease}

\section{Coronary heart disease (CHD)}

Physical inactivity is counted as one of the major risk factors of coronary heart disease based on the evidence of the surety, strength and causality of the association and the prevalence of physical inactivity ${ }^{54}$. It is also classified as predisposing risk factor because it has complex associations with several causal risk factors (e.g. high blood pressure, low HDL cholesterol and high plasma glucose) and conditional (causal link to CHD remains to be documented with certainty) risk factor (e.g. serum triglycerides, coagulation factors $)^{55}$. Some of the biological mechanisms by which physical activity may contribute to the prevention of CHD are presented in the previous tables and figures and they are summarized in Table $7^{56}$. These effects are caused mainly by endurance-type physical activities and many of them show a doseresponse pattern, a reliably measurable effect beginning usually as a result of moderate (intensity and volume) physical activity (see e.g. Fig. 1).

\section{Stroke}

Previous data have not unequivocally supported the preventive effect of physical activity on stroke ${ }^{4}$, but this kind of evidence has been increasing ${ }^{57-63}$. The variable findings may be explained partly by the different types of strokes (ischemic and haemorrhagic) with partly different risk factors and partly by uncertainties in assessing and differentiating (occupational and leisure time) physical activity in the old populations subjected to the risk of stroke. However, stroke is in major part an atherosclerotic disease and also in haemorrhagic stroke elevated blood pressure is an important risk factor. Physical activity has recently been included as a recommended measure in the prevention of a first stroke ${ }^{64}$.

\section{Cancer}

\section{Colon cancer}

Physical activity is associated with a reduced risk of colon cancer and biologically plausible mechanisms underlying this association are known, e.g. alterations in local 
Table 7 Biologic mechanisms by which exercise may contribute to the primary or secondary prevention of coronary heart disease ${ }^{\star 56}$

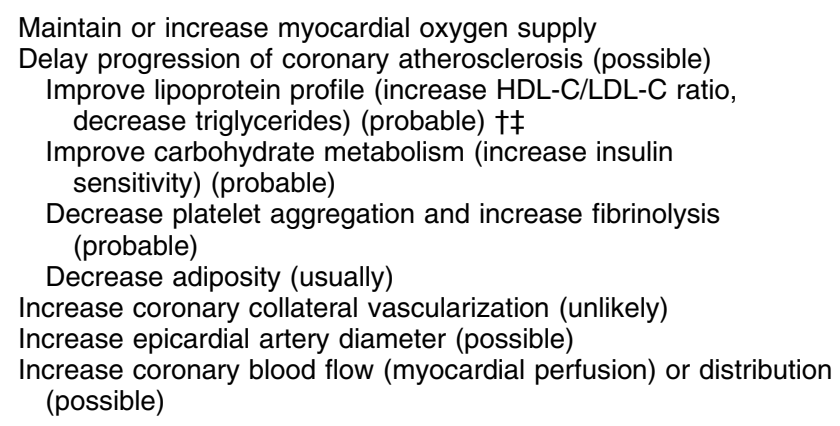

Decrease myocardial work and oxygen demand

Decrease heart rate at rest and submaximal exercise (usually)

Decrease systolic and mean systemic arterial pressure during submaximal exercise (usually) and at rest (usually)

Decrease cardiac output during submaximal exercise (probable)

Decrease circulating plasma catecholamine levels

(decrease sympathetic tone) at rest (probable) and at

submaximal exercise (usually)

Increase myocardial function

Increase stroke volume at rest and in submaximal exercise (likely) Increase ejection fraction at rest and during exercise (likely)

Increase intrinsic myocardial contractility (possible)

Increase myocardial function resulting from decreased 'afterload' (probable)

Increase myocardial hypertrophy (probable); but this may not reduce CHD risk $\S$

Increase electrical stability of myocardium

Decrease regional ischemia at rest or at submaximal exercise (possible)

Decrease catecholamines in myocardium at rest (possible) and at submaximal exercise (probable)

Increase ventricular fibrillation threshold due to reduction of cyclic AMO (possible) \|

* Expression of likelihood that effect will occur for an individual participating in endurance-type training program for 16 weeks or longer at $65 \%$ to $80 \%$ of functional capacity for 25 minutes or longer per session (300 kilocalories) for three or more sessions per week ranges from unlikely, possible, likely, probable, to usually.

† HDL $-\mathrm{C}=$ high-density lipoprotein cholesterol

‡ $\mathrm{LDL}-\mathrm{C}=$ low-density lipoprotein cholesterol

$\S \mathrm{CHD}=$ coronary heart disease

prostaglandin synthesis, increasing intestinal mobility, and decreased gastrointestinal transit time resulting in shorter contact time between the colon mucosa and potential carcinogens ${ }^{4,65-67}$.

\section{Other cancers}

Data regarding a relationship between physical activity and breast, endometrial, ovarian, prostate and testicular cancers are too limited or too inconsistent to allow firm conclusions. However, the accumulated supportive evidence and several plausible mechanisms for protective effects regarding particularly breast cancer warrant further research $^{4,68}$.

\section{Gallstone disease}

Relatively few studies have investigated the association between gallstone disease and physical activity and the
Table 8 Changes in immune system components after prolonged heavy exertion ${ }^{71}$

Neutrocytosis and lymphopenia, induced by high plasma cortisol

Increase in blood granulocyte and monocyte phagocytosis, but a ecrease in nasal neutrophil phagocytosis

Decrease in granulocyte oxidative burst activity

Decrease in nasal mucociliary clearance

Decrease in natural killer cell cytotoxic activity

Decrease in mitogen-induced lymphocyte proliferation (a measure of $T$ cell function)

Decrease in the delayed-type hypersensitivity response

Increase in plasma levels of pro- and anti-inflammatory cytokines (e.g. interleukin-6 and interleukin-1 receptor antagonist)

Decrease in ex vivo production of cytokines (interferon-y, interleukin-1 and interleukin-6) in response to mitogens and endotoxin

Decrease in nasal and salivary lgA level

Blunted major histocompatibility complex II expression in macrophages

results have been equivocal. Two recent studies add to the evidence supporting an inverse association ${ }^{69-70}$, and plausible mechanisms explaining this association can be proposed.

\section{Immune function and infections}

A bout of physical activity causes clear responses in several indices of the immune system. In general mild to moderate physical activity causes stimulation and hard (volume, intensity) activity suppression (Table 8$)^{71}$ of immune functions. Various nutritional supplements (vitamin C, glutamine, zinc and carbohydrate) have been tried in athletes to counteract the immune suppression but so far the results have been inconclusive ${ }^{72}$. Continuous physical training seems not to cause longlasting adaptive changes in the immune system but rather summation effects from acute responses to frequently repeating activity bouts. A possible exception is the significant elevation in the natural killer cell activity as a result of training. However, a few studies and experiences from competitive athletes suggest that very heavy acute or chronic exercise may increase the risk of upper respiratory tract infection, while moderate physical activity may reduce the symptoms of this condition ${ }^{73}$. These findings have led to the 'Inverted J Hypothesis' in exercise immunology (Fig. 5). As a whole, the area of exercise immunology is relatively new, and there are inconsistent findings on the immune responses and it is not yet clear whether some of the observed changes are beneficial or detrimental $^{74}$.

\section{Mental health and health-related quality of life}

The effects of physical activity on mental health and psychological well-being are less thoroughly studied than those related to biological health. Physical activity appears to decrease symptoms of depression, anxiety 


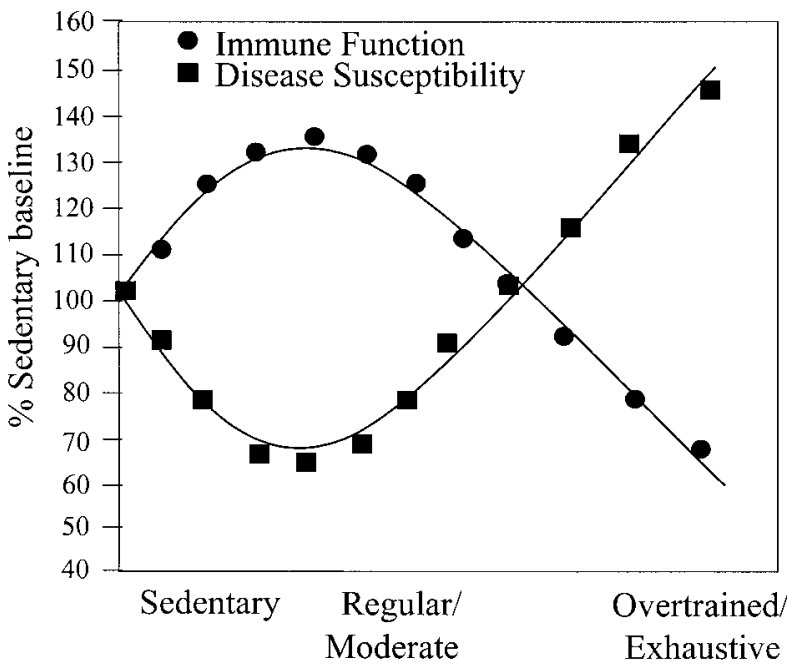

Training State /Exercise Dosage

Fig. 5 The 'Inverted J Hypothesis'73

and tension, and to improve mood. Regular physical activity may reduce symptoms of clinical unipolar depression $^{4,75}$ and the risk of developing depression, although further research is needed on this topic. Physical activity appears to improve health-related quality of life by enhancing psychological well-being (e.g., self-concept, self-esteem, mood, and affect) and by improving physical functioning, especially in persons compromised by poor health ${ }^{4}$. Engagement in physical activity may increase the psychological well-being independently of changes in cardiorespiratory fitness ${ }^{76}$. Several plausible, partly biological mechanisms to explain the psychological effects of physical activity have been suggested but more research is needed for their verification. ${ }^{4}$ The effects appear to depend strongly on individual and circumstantial factors, and thus they are less predictable than the biological effects ${ }^{77}$. Thus, beneficial activities on individual level are currently to a large extent a matter of personal experimentation.

\section{Summary}

In summary, regular physical activity causes numerous and substantial physiological performance improving and health-enhancing effects. These effects are seen especially in organs and functions primarily involved in physical activity, i.e. neuromuscular, cardiorespiratory and metabolic functions. Most of these effects are dose-dependent, highly predictable and generalizable to a wide range of population groups. Many of the biological effects of regular physical activity translate into decreased morbidity and mortality. This is especially true concerning degenerative diseases of the organ systems mentioned above and include some of the most common morbid or premorbid conditions of the populations of industrialised countries, such as coronary heart disease, cerebrovascular disease, hypertension, maturity onset diabetes, overweight and obesity, osteoporosis, and poor physical and health-related fitness. In these conditions causal link to lack of physical activity has been established with great certainty, and increased physical activity has been shown to decrease the risk of most of these conditions. The risk caused by physical inactivity is of the same order of magnitude as that of other modifiable risk factors of these conditions. The amount and type of physical activity that is needed to decrease the risk substantially is moderate in both absolute and relative terms, but only a minority and decreasing part of the populations in industrialised as well as in other countries is sufficiently physically active. All these facts taken together mean that the burden to population health caused by physical inactivity is very great and the potential to improve population health by increased physical activity is also great. Because sufficient physical activity for health is feasible to practice and very widely accepted among most population groups, a substantial part of the health potential of physical activity is likely to be realisable. However, there are a number of real and perceived individual and environmental obstacles hindering regular engagement in health-enhancing physical activity. Most of these obstacles can, however, be decreased by developing and implementing effective policies.

Nutrition and physical activity, two of the essential conditions of daily living, have strong, simultaneous and continuous influences on health. Adequate nutrition and physical activity improve health synergistically and partly additively, but inadequacies in one or the other lead to deleterious consequences. The basic metabolic pathways influencing health in positive or negative ways either through nutrition or physical activity are largely the same. It is obvious that policies and measures aimed at improving health have to include both nutrition and physical activity as strong components in order to be effective. Currently, development of nutrition policies are emphasized in most nations and international organisations, on legitimate grounds, but for the next adequate weight should be given also to develop and implement effective policies and measures to offer opportunities and incentives for health-enhancing physical activity for all population groups.

\section{References}

1 Haskell WL. The benefits of regular exercise. In: Nieman DC, ed. The exercise health connection. Champaign: IL: Human Kinetics, 1998: 301-9.

2 Haapanen-Niemi N, Vuori I, Pasanen M. Public health burden of coronary heart disease risk factors among middle-aged and elderly men. Prev. Med. 1999; 28: 343-8.

3 Haskell WL. Health consequences of physical activity: Understanding and challenges regarding dose-response. Med. Sci. Sports Exerc. 1994; 26: 649-66.

4 US Department of Health and Human Services, Centers for 
Disease Control and Prevention, National Center for Chronic Disease Prevention and Health Promotion. Physical activity and health: A Report of the Surgeon General. Atlanta, GA, 1996.

5 Killoran AJ, Fentem P, Caspersen C, eds. Moving on. International perspectives on promotion of physical activity. London: Health Education Authority, 1994.

6 Pan X-R, Li G-W, Hu Y-H, et al. Effects of diet and exercise in preventing NIDDM in people with impaired glucose tolerance. Diabetes Care 1997; 20(4): 537-44.

7 Wilmore JH, Costill DL. Physiology of sport and exercise. 2nd Edition. Champaign, IL: Human Kinetics, 1999.

8 Kraemer WJ, Fleck SJ, Evans WJ. Strength and power training: physiological mechanisms of adaptation. Exerc. Sport Sci. Rev. 1996; 24: 363-97.

9 Haapasalo H, Kannus P, Sievänen H, et al. Effect of long-term unilateral activity on bone mineral density of female junior tennis players. J. Bone Min. Res. 1998; 13: 310-9.

10 Vuori I. Peak bone mass and physical activity: a short review. Nutrition Reviews 1996; 54(4): S11-4.

11 Cummings SR, Nevitt HD, Browner WS, et al. Risk factors for hip fracture in white women. Study of Osteoporotic Fractures Research Group. N. Engl. J. Med. 1995; 332(12): $767-73$.

12 Crisso J, Kelsey J, O’Brien L, et al. Risk factors for hip fracture in men. Am. J. Epidemiol. 1997; 145: 786-93.

13 Gregg EW, Gauley JA, Seelye DG, et al. Physical activity and osteoporotic fracture risk in older women. Ann. Intern. Med. 1998; 129: 81-8.

14 Henderson KN, White CP, Eisman JA. The roles of exercise and fall risk reduction in the prevention of osteoporosis. Osteoporosis 1998; 27(2): 369-87.

15 Rutherford OM. Is there a role for exercise in the prevention of osteoporotic fractures? Br. J. Sports Med. 1999; 33: 378-83.

16 Ettinger WH Jr, Burns R, Messier SP, et al. A randomized trial comparing aerobic exercise and resistance exercise with a health education program in older adults with knee osteoarthritis. The Fitness Arthritis and Seniors Trial (FAST). JAMA 1997; 277: 25-31.

17 Cooper C, Coggon D. Physical activity and knee osteoarthritis. Lancet 1999; 353: 2177-8.

18 World Health Organization. International Society of Hypertension. Guidelines for the management of hypertension. $J$. Hypertens 1999; 17: 151-83.

19 Goldberg AP. Aerobic and resistive exercise modify risk factors for coronary heart disease. Med. Sci. Sports Exerc. 1989; 21: 669-74.

20 Chae CU, Lee IM, Ajani U, Hennekens CH, Manson JE. Physical activity and incidence of non-insulin dependent diabetes mellitus in the physician's health study. Am. J. Epidemiol. 1997; 145: 24.

21 Pan-EU survey on consumer attitudes to physical activity, body weight and health. Brussels, European Commission, 1999.

22 Wannamethee SG, Shaper AG, Walker M, Ebrahim S. Lifestyle and 15-year survival free of heart attack, stroke, and diabetes in middle-aged British men. Arch. Intern. Med. 1998a; 158: 2433-40.

23 Baan CA, Stolk RP, Grobbee DE, Witteman JCM, Feskens EJM. Physical activity in elderly subjects with impaired glucose tolerance and newly diagnosed diabetes mellitus. Am. J. Epidemiol. 1999; 149: 219-27.

$24 \mathrm{Hu} \mathrm{FB}$, Sigal RJ, RichEdwards JW, et al. Walking compared with vigorous physical activity and risk of type 2 diabetes in women. JAMA 1999; 282: 1433-9.

25 Manson J, Nathan D, Krolewski A, Stampfer M, Willett W, Hennekens M. A prospective study of exercise and incidence of diabetes among US male physicians. JAMA 1992; 268: 637.

26 Eriksson J, Taimela S, Eriksson K, Parviainen S, Peltonen J,
Kujala U. Resistance training in the treatment of non-insulindependent diabetes mellitus. Int. J. Sports Med. 1997; 18: 242-6.

27 Eriksson J, Tuominen J, Valle T, Sundberg S, Sovijärvi A. Aerobic endurance exercise or circuit-type resistance training for individuals with impaired glucose tolerance? Horm. Metab. Res. 1998; 30: 37-41.

28 Wallenberg-Henriksson H, Rincon J, Zierath J. Exercise in the management of non-insulin-dependent diabetes mellitus. Sports Med. 1998; 25: 25-35.

29 Dela F, Larsen JJ, Mikines KJ, Ploug T, Petersen LN, Galbo H. Insulin-stimulated muscle glucose clearance in patients with NIDDM. Effects of one-legged physical training. Diabetes 1995; 44(9): 1010-20.

30 Booth FW, Gordon SE, Carlson CJ, Hamilton MT. Waging war on modern chronic diseases: primary prevention through exercise biology. J. Appl. Physiol. 2000; 88: 774-87.

31 Wasserman DE, Ziman B. Exercise in individuals with IDDM. Diabetes Care 1994; 17: 924-37.

32 DeLany JP. Role of energy expenditure in the development of pediatric obesity. Am. J. Clin. Nutri. 1998; 68(suppl): 950S-5S.

33 Maffeis C, Talamini G, Tató L. Influence of diet, physical activity and parents' obesity on children's adiposity: a fouryear longitudinal study. Int. J. Obes. 1998; 22: 758-64.

34 Hernández B, Gortmaker SL, Colditz GA, Peterson KE, Laird NM, Parra-Cabrera S. Association of obesity with physical activity, television programs and other forms of video viewing among children in Mexico City. Int. J. Obes. 1999; 23: $845-54$.

35 Hill JO, Peters JC. Environmental contributions to the obesity epidemic. Science 1998; 280: 1371-4.

36 Hill JO, Melanson EL. Overview of the determinants of overweight and obesity: current evidence and research issues. Med. Sci. Sports Exerc. 1999; 31(11): S515-21.

37 Jebb SA, Moore MS. Contribution of a sedentary lifestyle and inactivity to the etiology of overweight and obesity: current evidence and research issues. Med. Sci. Sports Exerc. 1999; 31(11 Suppl): S534-41.

38 Byers T. Body weight and mortality. Editorial. New. Engl. J. Med. 1995; 333(11): 723-4.

39 Rissanen AM, Heliövaara M, Knekt P, Reunanen A, Aromaa A. Determinants of weight gain and overweight in adult Finns. Eur. J. Clin. Nutr. 1991; 45: 419-30.

40 Haapanen N, Miilunpalo S, Pasanen M, Oja P, Vuori I. Association between leisure time physical activity and 10year body mass change among working-aged men and women. Int. J. Obes. 1997; 21: 288-96.

41 Clinical Guidelines on the Identification, Evaluation, and Treatment of Overweight and Obesity in Adults. The Evidence report. US Department of Health and Human Services, National Institutes of Health, National Heart, Lung, and Blood Institute. 1998.

42 Grundy SM, Blackburn G, Higgins M, Lauer R, Perri MG, Ryan D. Physical activity in the prevention and treatment of obesity and its comorbidities. Med. Sci. Sports Exerc. 1999; 31(11 Suppl): S502-8.

43 Garrow JS, Summerbell CD. Meta-analysis: effect of exercise, with or without dieting on body composition of overweight subjects. Eur. J. Clin. Nutr. 1995; 49: 1-10.

44 Smith SR, Zachwieja JJ. Visceral adipose tissue: a critical review of intervention strategies. Int. J. Obes. 1999; 23: 32935.

45 Levine JA, Eberhardt NL, Jensen MD. Role of nonexercise activity thermogenesis in resistance to fat gain in humans. Science 1999; 283: 212-4.

46 Weyer C, Linkeschowa R, Heise T, Giesen HT, Spraul M. Implications of the traditional and the new ACSM Physical Activity Recommendations on weight reduction in dietary treated obese subjects. Int. J. Obes. 1998; 22: 1071-8. 
47 Andersen RE, Wadden TA, Bartlett SJ, Zemel B, Verde TJ, Franckowiak SC. Effects of lifestyle activity vs structured aerobic exercise in obese women. A randomized trial. JAMA 1999; 281: 335-40.

48 Obesity: preventing and managing the global epidemic: report of a WHO Consultation on Obesity, Geneva, June 3-5, 1997. Geneva: World Health Organization, 1998

49 Willett W, Dietz W, Colditz GA. Guidelines for healthy weight. New. Engl. J. Med. 1999; 341(6): 427-34.

50 Wolf AM, Colditz GA. Current estimates of the economic costs of obesity in the United States. Obes. Res. 1998; 6: 97106.

51 Blair SN, Brodney S. Effects of physical inactivity and obesity on morbidity and mortality: current evidence and research issues. Med. Sci. Sports Exerc. 1999; 31(11 Suppl): S646-62.

52 Lee CD, Blair SN, Jackson AS. Cardiorespiratory fitness, body composition, and all-cause and cardiovascular disease mortality in men. Am. J. Clin. Nutr. 1999; 69: 373-80.

53 Wei M, Kampert JB, Barlow CE, et al. Relationship between low cardiorespiratory fitness and mortality in normal-weight, overweight, and obese men. JAMA 1999; 282: 1547-53.

54 Fletcher GF, Blair SN, Blumenthal J, et al. Statement on exercise: benefits and recommendations for physical activity programs for all Americans: a statement for health professionals by the Committee on Exercise and Cardiac Rehabilitation of the Council on Clinical Cardiology, American Heart Association. Circulation 1992; 86: 340-4.

55 Grundy SM. Primary prevention of coronary heart disease. Integrating risk assessment with intervention. Circulation 1999; 100: 988-98.

56 Haskell WL. Physical activity, lifestyle, and cardiovascular health. In: Leon AS, ed. Physical activity and cardiovascular health. A national consensus. Champaign, IL: Human Kinetics, 1997.

57 Haheim LL, Holme I, Hjermann I, Leren P. Risk factors of stroke incidence and mortality. A 12-year follow-up of the Oslo study. Stroke 1993; 24(10): 1484-9.

58 Lindenström E, Boysen G, Nyboe J. Lifestyle factors and risk of cerebrovascular disease in women. The Copenhagen City Heart Study. Stroke 1993; 24: 1468-72.

59 Abbott RD, Rodriquez BL, Burchfiled CM, Curb JD. Physical activity in older middle-aged men and reduced risk of stroke. The Honolulu heart program. Am. J. Epidemiol. 1994; 139: 881-93.

60 Shinton R. Lifelong exposures and the potential for stroke prevention. The contribution of cigarette smoking, exercise and body fat. J. Epidemiol. Community Health 1997; 51: $138-43$.

61 Lee IM, Paffenbarger RS. Physical activity and stroke incidences. The Harvard Alumni Health Study. Storke 1998; 29: 2049-54.

62 Sacco RL, Gan R, Boden-Albala B, et al. Leisure-time physical activity and ischemic stroke risk. The Northern Manhattan Stroke Study. Stroke 1998; 29: 380-7.
63 Wannamethee SG, Shaper AG, Walker M. Changes in physical activity, mortality, and incidence of coronary heart disease in older men. Lancet 1998b; 351: 1603-8.

64 Gorelick PB, Sacco RL, Smith DB, et al. Prevention of a first stroke. A review of guidelines and a multidisciplinary consensus statement from the National Stroke Association. JAMA 1999; 281(12): 1112-20.

65 Thune I, Lund E. Physical activity and risk of colorectal cancer in men and women. Br.J. Cancer 1996; 73: 1134-40.

66 Martínez ME, Giovannucci E, Spiegelman D, Hunter DJ, Willett WC, Colditz GA. Leisure-time physical activity, body size, and colon cancer in women. Journal of the National Cancer Institute 1997; 89(13): 948-55.

67 Slattery ML, Potter J, Caan B, et al. Energy balance and colon cancer - beyond physical activity. Cancer Res 1997; 57: 7580 .

68 McTiernan A. Exercise and breast cancer - time to get moving? N. Engl. J. Med. 1997; 336: 1311-2.

69 Leitzmann MF, Rimm EB, Willett WC, et al. Recreational physical activity and the risk of cholecystectomy in women. New. Engl. J. Med. 1999; 341(11): 777-84.

70 Misciagna G, Centonze S, Leoci C, Guerra V, Cisternino AM, Ceo R, Trevisan M. Diet, physical activity, and gallstones - a population-based, case-control study in southern Italy. Am.J. Clin. Nutr. 1999; 69: 120-6.

71 Nieman DC, Pedersen BK. Exercise and immune function. Recent developments. Sports Med. 1999; 27(2): 73-80.

72 Shephard RJ, Shek PN. Associations between physical activity and susceptibility to cancer. Sports Med. 1998; 26(5): 293315.

73 Woods JA, Davis JM, Smith JA, Nieman DC. Exercise and cellular innate immune function. Med. Sci. Sports Exerc. 1999; 31(1): 57-66.

74 Mackinnon LT. Advances in exercise immunology. Champaign, IL: Human Kinetics, 1999.

75 Martinsen EW, Stephens T. Exercise and mental health in clinical and free-living populations. In: Dishman RK, ed. Advances in exercise adberence. Champaign, IL: Human Kinetics, 1994: 55-72.

76 Rejeski WJ, Brawley LR, Shumaker SA. Physical activity and health-related quality of life. Exerc. Sport Sci. Rev. 1996; 24 71-108.

77 Ekkekakis P, Petruzzello SJ. Acute aerobic exercise and affect. Current status, problems and prospects regarding dose-response. Sports Med. 1999; 28(5): 337-374.

78 Bouchard C. Physical activity and prevention of cardiovascular diseases: potential mechanisms. In: Leon AS, ed. Physical Activity and Cardiovascular Health. A Notional Consensus. Champaign; IL: Human Kinetics, 1997: 48-56.

79 Barnard RJ, Wen SJ. Exercise and diet in the prevention and control of the metabolic syndrome. Sports Med 1994; 18(4): 218-228. 